\title{
Modelling the effects of destructive fishing practices on tropical coral reefs
}

\author{
S. B. Saila ${ }^{1}$, V. Lj. Kocic ${ }^{2}$, J. W. McManus ${ }^{1}$ \\ ${ }^{1}$ International Center for Marine Resource Development, ${ }^{2}$ Mathematics Department \\ The University of Rhode Island, Kingston, Rhode Island 02881, USA
}

\begin{abstract}
A literature review of the use of underwater explosives indicated that the largest lethal zone for swimbladder fishes is located near the surface of the water. Mortality in this zone is due to rupture of the swimbladder from negative pressure induced by cavitation of the near-surface water volume from a subsurface explosion. Observational studies of blast fishing in the Philippines indicated that valuable pelagic species rather than typical coral reef species were the primary targets. Empirical data on the extent of various destructive fishing practices (blast fishing, anchor damage, and use of poisons), as well as coral regrowth estimates, provided inputs to a nomographic model of the reef ecosystem. The model provided time graphs of fish diversity and the amount of coral regrowth under various conditions. The results of the simulation model studies indicated that the sum of all current destructive practices was sufficient to continue loss of diversity and loss of live coral cover for about $25 \mathrm{yr}$ before any recovery was expected. On the other hand a reduction in the rate of destructive fishing to about $30 \%$ of the current level would permit continuing slow recovery of both diversity and live coral cover. Available observational information suggests that this might best be accomplished by attempting to eliminate the use of poisons (such as cyanide) in reef areas and reducing anchor damage in addition to reducing blast fishing in coral areas. The probable effects of the latter may have been overemphasized in the past.
\end{abstract}

\section{INTRODUCTION}

Schweitzer (1992) broadly defined methods for conserving biodiversity in developing countries and indicated that efforts to protect biological diversity in these areas must accommodate the demand for renewable natural resources. Fishing is an important activity in the developing world. Destructive fishing practices are common in tropical coral reef regions where a large human population and severe economic duress combine to promote a state of desperation among the fishers. Use of explosives in fish capture (blast fishing) and use of certain poisons (e.g. sodium cyanide) are usually defined as destructive fishing practices in the sense that physical and/or physiological damage occurs to the coral reef habitat in the process of fish capture. However, physical damage to coral reefs is also associated with a variety of reef fishing operations which involve anchoring boats on the reef or using fishing gear which physically damages the reef. The extent of these destructive fishing practices and their probable impacts on the coral environment and fish assemblages are not well known at present. Destructive fishing practices have 2 major effects on coral reef fish communities. They lead to loss of coral cover which reduces both fish abundance and diversity over time unless coral regrowth is adequate to compensate for the loss.

Russ (1991) has recently provided a comprehensive review of the effects of fishing on coral reef fisheries as well as some yield estimates. However, he did not describe destructive fishing practices in detail other than mentioning habitat modification as a result of the use of explosives for fishing. Some specific references to destructive fishing practices include Alcala \& Gomez (1987), Galvez \& Sadorra (1988), Pauly et al. (1989), Galvez et al. (1989), and Rubec (1988). The last 2 citations include references to the use of cyanide in fish capture. Although it is suggested that these practices may have significant adverse consequences, none of the above-mentioned references provide information to quantitatively assess these practices. Shephard et al. 
(1992) analyzed fish community response to coral mining in the Maldives. They demonstrated significant effects of coral mining using multivariate classification and ordination methods on relative abundances and species biomass. This work was designed primarily to detect changes in community composition and the species responsible for these changes, and provided an excellent review of methods used to date for assessing damage. The objective of our work was to contribute to a better understanding of destructive fishing practices with special reference to blast fishing. We first examine available empirical information from the Philippines and attempt to theoretically understand the effects of underwater explosions for fish capture. We then apply a model which quantifies the effects of destructive fishing practices as measured by the rates of change in diversity, based on the extent of the perturbed coral area and rates of coral destruction and regrowth.

Smith (1978) estimated that there are about $617000 \mathrm{~km}^{2}$ of coral reefs in the world. Assuming a fisheries yield of 8 metric tons (mt) $\mathrm{km}^{-2} \mathrm{yr}^{-1}$ for coral reefs and adjacent areas, Smith (1978) estimated a potential yield of about 6 million $\mathrm{mt}$ from these areas globally. Although this yield is not currently realized, fish production on coral reefs is thought to be higher than from any other natural fish production system (Longhurst \& Pauly 1987). In view of their high economic and ecological value, information contributing to the sustainability of reef yields and to maintaining high biodiversity is considered useful.

The major emphasis thus far in the scientific community has involved studies of the effects of tropical deforestation on biodiversity. Other ecosystems may be of considerable significance as well. For example, it should be recalled that the global coastal zone occupies about $8 \%$ of the earth's surface (Ketchum 1972) and more than $50 \%$ of the entire human population lives within or near this zone. Furthermore, tropical coral reefs and shallow coastal seas (especially in Southeast Asia) contain the most diverse fish communities in the world. It seems clear that increased attention must be given to tropical coastal areas and coral reefs as centers of biological diversity, not only because they contain large numbers of species but also because these environments are being subjected to increasingly severe perturbations by man. This study represents an initial effort to quantify what is currently known about destructive fishing practices in coral reef areas. Modelling is an appropriate technique for preliminary assessment of the rates of destruction and regrowth of coral reefs and probable changes in biodiversity. We clearly recognize that our approach is a simplification of reality, and its limitations with respect to the accuracy and precision of input parameters are acknowledged.

\section{STUDY SITE}

The primary observational data used for model development was gathered from the reef flat and reef slope areas near Santiago Island, located on the western tip of the Lingayen Gulf, Luzon, the Philippines. This small island (about $10 \mathrm{~km}$ in longest dimension) supports approximately 1000 families with an average of 6 members per family. The coral reef flat and slope are subjected to what has been described by Pauly et al. (1989) as Malthusian overfishing. This is said to occur when poor fishermen, faced with declining catches and lacking any other alternative, initiate wholesale resource destruction in an effort to maintain their incomes. Included in this are destructive fishing practices, which utilize explosives and sodium cyanide. McManus et al. (1991) clearly described the study area, the fisheries, and the methods used for gathering the field data utilized in this study. For the purposes at hand, we tabulate only those summary data from the above reference which were used directly in the simulation model studies or data considered relevant for background. Table 1 summarizes some aspects of the study site and inputs used in the model. This summary table is the result of more than 4 yr of intensive study by a team of scientists from the University of the Philippines and the University of Rhode Island.

Table 1. Summary of some relevant physical and biological information from the Santiago Island area of Luzon, Philippines and the data used in the simulation modelling. This material is condensed from Tables 1 \& 2 and text of McManus et al. (1991)

\begin{tabular}{|c|c|c|c|}
\hline Description & \multicolumn{3}{|c|}{ Approximate dimension } \\
\hline \multicolumn{2}{|l|}{ Area of reef flat } & \multicolumn{2}{|l|}{$24 \mathrm{~km}^{2}$} \\
\hline \multicolumn{2}{|l|}{ Area of reef slope } & \multicolumn{2}{|l|}{$60 \mathrm{~km}^{2}$} \\
\hline \multicolumn{2}{|l|}{ No of reef slope fish species } & \multicolumn{2}{|l|}{1000} \\
\hline \multicolumn{2}{|c|}{ No of scleractinean coral species } & \multicolumn{2}{|l|}{$300-500$} \\
\hline \multicolumn{2}{|c|}{ Current extent of damaged coral } & \multicolumn{2}{|l|}{$50 \%$} \\
\hline \multicolumn{4}{|c|}{$\begin{array}{l}\text { Estimated percent coral lost per year from various prac- } \\
\text { tices and coral regrowth derived from observational data }\end{array}$} \\
\hline \multirow[t]{2}{*}{ Activity } & \multicolumn{3}{|c|}{ Loss $\left(\% \mathrm{yr}^{-1}\right)$} \\
\hline & $\begin{array}{l}\text { Worst } \\
\text { case }\end{array}$ & $\begin{array}{l}\text { Moderate } \\
\text { case }\end{array}$ & $\begin{array}{l}\text { Best } \\
\text { case }\end{array}$ \\
\hline Blast fishing & 13 & 0.44 & 0.02 \\
\hline Cyanide and other poisons & 9.5 & 2 & 0.002 \\
\hline Anchor damage & 5 & 0.4 & 0.004 \\
\hline Total & 27.5 & 2.84 & 0.026 \\
\hline Coral regrowth $\left(\% \mathrm{yr}^{-1}\right)$ & 0.1 & 1.0 & 9 \\
\hline
\end{tabular}




\section{DESTRUCTIVE FISHING METHODS}

We will briefly describe some of the destructive fishing methods with particular emphasis on blast fishing. Since blast fishing has been alleged to pose a serious threat to the fishing industry and to the environment in areas where it is regularly practiced, it is appropriate to consider the practices employed and results achieved by fishermen in the Lingayen Gulf and to briefly describe what seems to be known about the effects of underwater explosions on fish and other marine organisms. In the Lingayen Gulf 3 families of fishes (Carangidae, Mugilidae, and Siganidae) dominate the catches of blast fishermen. These are highvalue fishes in the Philippines, but lesser-valued densely schooling small fishes - such as anchovies are also targeted. Overall, more than 24 families and 75 species have been recorded from the catches of blast fishermen over the period of observation. The family composition of the catch clearly indicates that much blast fishing is carried out with the intent of catching valuable pelagic species. On the other hand, as will be shown, there may be some physical damage to corals and to coral-associated fishes due to the tactics applied in blast fishing even when the targeted species are pelagic.

We will not specifically consider the various types of explosives which have been used. McManus et al. (1991) describe the materials and methods utilized in the Philippines. Instead we will try to describe the probable effects of underwater explosions, with emphasis on fish with swimbladders. As correctly stated by Gordon (1970), a large part of the literature on pressure effects of explosions resides in reports to government agencies, and some of these are not easily accessible. It is fortunate that a recent Naval Surface Warfare Center report by Young (1991) effectively summarized some methods for predicting the effects of underwater explosions on marine life. We utilize the prediction equations and vulnerability categories from Young (1991) for non-swimbladder fishes and other marine organisms - as well as for fish with swimbladders - to corroborate some of our observational results. Material which follows is aiso condensed from Christian (1973) and others with a view toward providing a synthesis of currently available information.

A typical underwater explosion generates a spherical shock wave, assuming the explosion takes place off the bottom. The peak pressure amplitude $p_{\max }$ at a particular range $R$ is related to the weight of the charge $W$ by:

$$
p_{\max }=k\left(W^{1 / 3} / R\right)^{1.13}
$$

In Eq. (1) the proportionality constant $k$ depends on the type of explosive material. In general fast-burning explosives such as TNT are more effective in killing fishes than the slower-burning ones, such as black powder, as shown by Hubbs \& Rechnitzer (1952). The explosion effect commonly thought to cause mortality to fish in the past is the high pressure wave associated with the explosion. We use the TNT peak pressure wave (Arons 1954) to further develop our understanding of fish kills from underwater explosions. Define units of pressure in pounds per square inch (psi) and range in feet (ft). The value of $k=2.16 \times 10^{4}$ for TNT. If some particular peak pressure $p_{\mathrm{L}}$ (psi) is taken as a criterion for lethality, it is possible to write the corresponding equation for lethal range $R_{\mathrm{L}, \mathrm{p}}(\mathrm{ft})$ in terms of the weight of the explosive $W$ (pounds) as:

$$
R_{\mathrm{L}, p}=C \cdot W^{1 / 3}
$$

where $C=6852 p_{\mathrm{L}}^{-0.885}$. Some estimates of $70 \mathrm{psi}$ for onset and 180 psi for certain lethality were provided by NOL (1947) to give $C$ values of 166 for onset and 69 for certain lethality.

From Eqs. (1) \& (2), it is evident that doubling the weight of explosive charge does not double its effective range. The shock wave scales roughly as the cube root of the charge weight as will be demonstrated. The equation provided by Young (1991) for $90 \%$ survivability of flounder (a non-swimbladder fish) is:

$$
R_{\mathrm{FL}}=3.38 W_{\mathrm{E}}^{1 / 3}
$$

where $R_{\mathrm{FL}}=$ range in feet for $90 \%$ survivability; $W_{\mathrm{E}}=$ weight of explosive in pounds. Substituting 1.5 pounds in Eq. (3) provides an $R_{\mathrm{FL}}$ value of $3.87 \mathrm{ft}(=1.18 \mathrm{~m})$. It is necessary to raise the weight of explosive to 12 pounds in order to double the value of $R_{\mathrm{FL}}$ to $7.75 \mathrm{ft}(=2.36 \mathrm{~m})$. In general, we believe Eq. (3) is valid for fish without swimbladders although it was apparently derived for flounder. Young (1991) also provided equations of similar form for shrimp, lobster, oysters, and crabs. Of these non-swimbladder organisms, the flounder was the most resistant to the shock wave from underwater explosions followed by the above groups of organisms in the order listed. The functional forms of the equations for the lethal range (Eqs. $2 \& 3$ ) implies that the lethal zone is symmetric in all directions around the charge and that damage is directly related to the pressure wave sent out by the explosion. This may be the case very close to the explosion, but fish kills have been observed at far greater ranges from the explosion source, with no visible manifestation of damage except a ruptured swimbladder. These observations coupled with the observation that fish kills tend to be greater at shallow depths than near the bottom provide some preliminary indication of which portions of the explosive pressure field seem to be most damaging to fish with swimbladders. Work described by Hogan (1941) demonstrated that physostomous fish (with open swim- 
bladders connected to the alimentary canal) were better able to withstand negative pressures than physoclistous fish (with closed swimbladders). The 'bottom line' appears to be that swimbladders of fish literally explode when fish are within the lethal zone of an explosion and that those fish with closed swimbladders are most vulnerable. This provides preliminary evidence that it is the negative pressure induced by tension rather than compression forces which produces the relatively large range of kills observed near the surface from blast fishing. Our observational information is supported by a general equation for predicting $90 \%$ survivability for fish with swimbladders presented by Young (1991) as follows:

$$
R_{\mathrm{SF}}=95 W_{\mathrm{F}}^{-0.13} W_{\mathrm{E}}^{0.28}(\mathrm{DOB})^{0.22}
$$

where $R_{\mathrm{SF}}=$ range in feet for swimbladder fishes; $W_{\mathrm{F}}=$ weight of fish in pounds; $\mathrm{DOB}=$ depth of burst in feet; and $W_{E}=$ weight of explosive in pounds as used previously, Substituting 1.5 pounds for $W_{E}, 0.5$ pounds for $W_{\mathrm{F}}$, and $10 \mathrm{ft}$ for $\mathrm{DOB}$, we find for $90 \%$ survivability $\left(R_{\mathrm{SF}}\right)$ to be $207 \mathrm{ft}(=63.1 \mathrm{~m})$. This is nearly 3 orders of magnitude greater than the range for nonswimbladder fishes determined from Eq. (3) using the same charge weight. Within limits, increasing the depth of burst (DOB) will increase the value of $R_{\mathrm{SF}}$ as will increasing the weight of explosive when other factors are held constant. However, the negative power for $W_{F}$ (the weight of fish) indicates that smaller fish are more vulnerable than large fish. In general, our field observations and the findings summarized by Young (1991) indicate that swimbladder fish near the surface are more vulnerable than those found in deeper water.

As indicated previously, a typical underwater explosion generates a spherical shock wave. Peak pressure at the front end of the wave decreases with range as shown in Eq. (1). Pressure behind the front initially decreases exponentially with time and then more slowly. When the shock wave hits the air (water interface) a tension wave, which is the inverted image of the pressure wave, is reflected back into the water. However, if the compression wave is still of relatively high amplitude when it reaches the surface, the above description of a tension wave is not valid. When the negative pressure is lower than the critical breaking pressure, the water is actually torn into many bubbles by the surface-reflected shock wave. That is, the water is cavitated. Since available empirical evidence correlates fish mortality with negative pressures from the explosion, a method is required for estimating both pressure values as well as the location and geometry of the cavitated region for various depths and types of explosive charge. Clearly, Eq. (4) does not quantitatively account for the geometry of the zone of cavitation.
Without going into further details regarding the cavitation zone, it seems that Philippine blast fishermen have empirically determined that by allowing a charge to reach a certain critical depth, the horizontal span of the cavitation zone can be substantially increased using a constant weight of explosives. Clearly, there is a limit to the increase in depth which maximizes the cavitation zone for a given explosive charge. However, for the purposes at hand, the important result from the above explanation is that the major zone of fish lethality (for swimbladder fishes) coincides with the zone of bulk cavitation and consists of a shallow region located above the subsurface explosion. The other lethal zone is, of course, within a very small radius of the charge where virtually everything is destroyed by the positive pressure wave. This has been estimated at 1 to $2 \mathrm{~m}$ in the Philippine studies, and it is supported by the prediction equation (Eq. 3) for non-swimbladder fish provided by Young (1991). It seems worth repeating here that organisms which do not have swimbladders are likely to be killed only in the immediate vicinity of an underwater explosion, and the larger, near-surface zone associated with bulk cavitation significantly affects only organisms with swimbladders. The reason is that a rupturing (explosion) of the swimbladder is caused by the negative pressure amplitude associated with cavitation. The radius of this zone may be on the order of 10 to $20 \mathrm{~m}$ for the typical charge used in the Philippines, but its geometry is very variable depending on the depth of the explosion and its intensity.

Regrettably, at this time there is much less information available concerning the lethality of various toxic substances used in fish capture to living corals. Some artisanal fishermen cited in Galvez et al. (1989) provide a case study of the use of sodium cyanide in fishing and report that a segment of artisanal fishers (primarily blast fishers) believe a major cause for declining fish catches is the rampant use of sodium cyanide. They think that corals exposed to sodium cyanide acquire foul odors which keep fish away and that the affected corals eventually die. This belief is not shared by the cyanide users who believe it dissipates quickly with little harm. Clearly, considerable research needs to be done to ascertain with greater objectivity the effects of sodium cyanide on the live coral habitat. Our studies suggest that this effect may be greater than the combined effects of blast fishing and anchor damage in the moderate case.

The effects of anchor damage are measurable, and McManus et al. (1991) have indicated the magnitude of this problem in the Philippines. Allen (1992) has documented anchor damage to reefs from large vessels, as well as providing an overview of anchor damage and tourism threats in the Caribbean area. Comments on Allen's article by McClanahan (1992) suggest that 
destructive fishing practices may have more impact on reef ecology then tourism and threats from recreational use of coral reef areas based on experience in Kenya. In brief, anchor damage on some reefs may equal or exceed that from blast fishing in the Philippines. Methods for reducing this physical damage from anchors used by artisanal fishermen seem well worth further study and may be easier to implement than reducing other destructive fishing practices.

\section{MODEL DESCRIPTION}

The model utilized by us is an extension of the nomographic species area approach used in a study of deforestation effects on diversity by Kangas (1991). In our application the species area curve is used to predict local extinctions of fish due to loss of coral habitat by destructive fishing practices. In the nomographic species area approach one moves backward along the species area curve for a distance equivalent to the amount of habitat destruction. The curve is then used as a nomograph to find the number of species that can be expected in the remaining area. The distance between the initial diversity and the remaining diversity is the number of extinctions due to habitat loss. Prediction of the diversity loss is dependent on the slope of the species area curve. Species area curves have been used to predict the number of species that would be expected to go extinct with reductions in a refuge area (Soulé et al. 1979) and to predict extinctions due to habitat destruction (Lovejoy 1980).

The model contains an explicit relationship between the amount of coral reef covered with live corals and the biodiversity of the associated fish assemblage. This biodiversity is measured as species richness expressed as the number of species. The most commonly used model for the species area curve is the power function relationship

$$
S=c A^{Z}
$$

where $S=$ number of species; $A=$ area; $c=$ a coefficient or intercept in a log-transformed linear equation; and $Z=$ the exponent of a power function or the regression slope in a log-transformed linear equation. For a variety of taxa, the slope is near 0.25 (Gould 1979). This value has been utilized in our work, and it has also been employed by both Simberloff (1986) and Kangas (1991). We are aware of some of the problems of statistical estimation of this parameter as described by Loehle (1990). However, we use it as an average value derived from actual data. Sugihara (1981) provides further justification for the use of a value of 0.25 for this coefficient. A range of $Z$ values $(0.15<Z<0.35)$ has been suggested by Wissel (1992).
Coral regrowth was incorporated into our model, and we provide a choice of linear $(y=a+b x)$, quadratic $\left(y=a+b x+c x^{2}\right)$, or exponential function $[y=a \exp$ $(b x)]$ to simulate increasing/decreasing rates of coral destruction. Kangas (1991) provided a ramp function which increases over time at a linear rate for his forest biodiversity studies.

The general nomographic species model is defined as follows:

$$
\begin{aligned}
D(t) & =K A(t)^{2} \\
\frac{\mathrm{d} A(t)}{\mathrm{d} t} & =-k_{3} E(t) A(t) \\
\frac{\mathrm{d} C(t)}{\mathrm{d} t} & =-k_{4} E(t) A(t)
\end{aligned}
$$

where $D=$ diversity; $A=$ area of coral reef; $Z=$ an exponent in the species area curve; $C=$ initial area of destroyed reef; $K=$ a rate coefficient; and $E=$ an energy source term.

The initial conditions for the state variables in the model were: $A_{0}=100 \%$, and $D_{0}$ is calculated as a function of $A$ and starts at $100 \%$ at $A=A_{0}$.

For the rate coefficients the following conditions apply. The energy source $(E)$ is scaled to unity. From Table 1 the rate of reef destruction from all causes (blast fishing, poisons, and anchor damage) is estimated to be $2.84 \% \mathrm{yr}^{-1}$ of the remaining area in the moderate (best estimate) case.

$$
\begin{aligned}
& \text { Let } 2.84=-k_{3} E A, \text { using } E=1 \text { and } A=100 . \\
& \text { Then } k_{3}=2.84 /(1 \times 100)=0.0284=\frac{d C}{d t} .
\end{aligned}
$$

Regrowth of coral at $1 \% \mathrm{yr}^{-1}$ was estimated for the moderate (best estimate) case.

$$
\begin{gathered}
1.0=k_{4} C \\
\text { Using } C=50, k_{4}=1.0 / 50=0.020 .
\end{gathered}
$$

The simulation model was implemented by replacing the simple difference equation formulation of the model of Kangas (1991) with the Runge-Kutta method for the numerical solution of the initial value problem for ordinary differential equations. We also permit complete flexibility for changing all input parameters for each run. A FORTRAN 77 program was written for the simulation model and is available from the authors.

\section{RESULTS}

Simulations were carried out for a period of $100 \mathrm{yr}$ in all cases. Fig. 1 illustrates the results obtained from what is taken to be the most likely set of input values. These include the assumption that $50 \%$ of the initial 


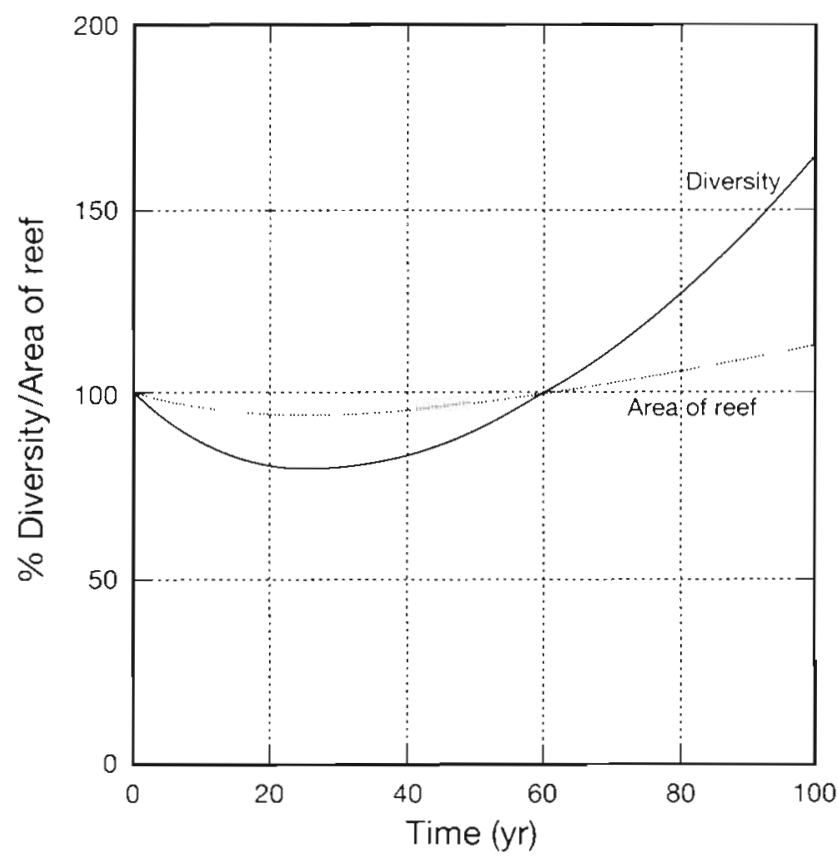

Fig. 1. Time graphs showing relationships between coral reef fish assemblage diversity and area of reet with coral cover over $100 \mathrm{yr}$. Simulation model inputs were: $Z=0.25, C=50 \%$, $\mathrm{d} C / \mathrm{d} t=2.84 \%$, and coral reef regrowth $=1 \% \mathrm{yr}^{-1}$. This figure illustrates what are believed to be the best available (moderate case) estimates for model inputs derived from the study area in Luzon, Philippines. Constant rate coefficients are assumed for all inputs

live coral cover $\left(C_{0}=50\right)$ has already been destroyed, $\mathrm{d} C / \mathrm{d} t=2.84 \%$, and regrowth occurs at $1 \% \mathrm{yr}^{-1}$. A constant energy source $[E(t)=1]$ and rate of reef destruction and recovery are assumed for this simulation. The results (Fig. 1) indicate that diversity ( $D$ ) will decline for about 25 yr to approximately $80 \%$ of its initial value $(C=50$, but taken as $100 \%$ in the figure for illustrative purposes) and then will recover to about 1.65 times its initial value after 100 yr. The area of live coral will also continue to decline for about the same period of time after which it begins to recover, but at a rate which approaches 1.13 times its initial value after 100 yr. Although not illustrated by a figure, the worst case scenario $(\mathrm{d} C / \mathrm{d} t=27.5 \%$ with a regrowth of $0.1 \%$ with $C=50$ ) showed extreme losses of diversity and coral reef area within 20 yr to about $1.3 \%$ of initial diversity and to $34 \%$ of the initial coral reef area. Another scenario $(\mathrm{d} C / \mathrm{d} t=0.44 \%$ and regrowth of $0.1 \% \mathrm{yr}^{-1}$ with $\mathrm{C}=50$ ) showed continuous increases in diversity to about 2 times the initial values and about a $15 \%$ increase in coral cover over a 100 yr period. This scenario represents the modelling of blast fishing effects alone, assuming a constant rate of destruction of coral habitat and a conservative estimate of coral regrowth rate of $0.1 \% \mathrm{yr}^{-1}$.
The time graph of diversity changes as a function of the extent of initially destroyed area is shown in Fig. 2. Note that the starting point is scaled to 100 in all cases. It is evident from this figure that the rate of increase in diversity is much higher for the cases where the smallest amount of coral reef has been destroyed initially. All conditions in Fig. 2 are identical to Fig. 1 except that $\mathrm{d} C / \mathrm{d} t$ is assumed to be 0.44 to simulate the moderate case for blast fishing only.

The time graph of coral reef area changes as a function of the extent of the initially destroyed area (Fig. 3) with conditions identical to Fig. 2. It is evident that the rates of increase and the percentage increases over the $100 \mathrm{yr}$ time span are substantially smaller for the live coral cover than for diversity. These differences are believed to be due to the nonlinear form of the species area relationship and the relatively slow growth rates of corais.

When a linear model of increasing coral reef destruction is applied (see Fig. 4 for details), it is evident that there is a substantial decrease in diversity and more reduction in coral habitat/cover than with the constant rate model of Fig. 1 with similar input parameters. Recovery, in the case of the linear model, appears to be initiated after approximately $40 \mathrm{yr}$ in contrast to about $25 \mathrm{yr}$ for the constant rate model, but it does not reach the initial value condition even after 100 yr. This holds for both coral reef area and diversity changes.

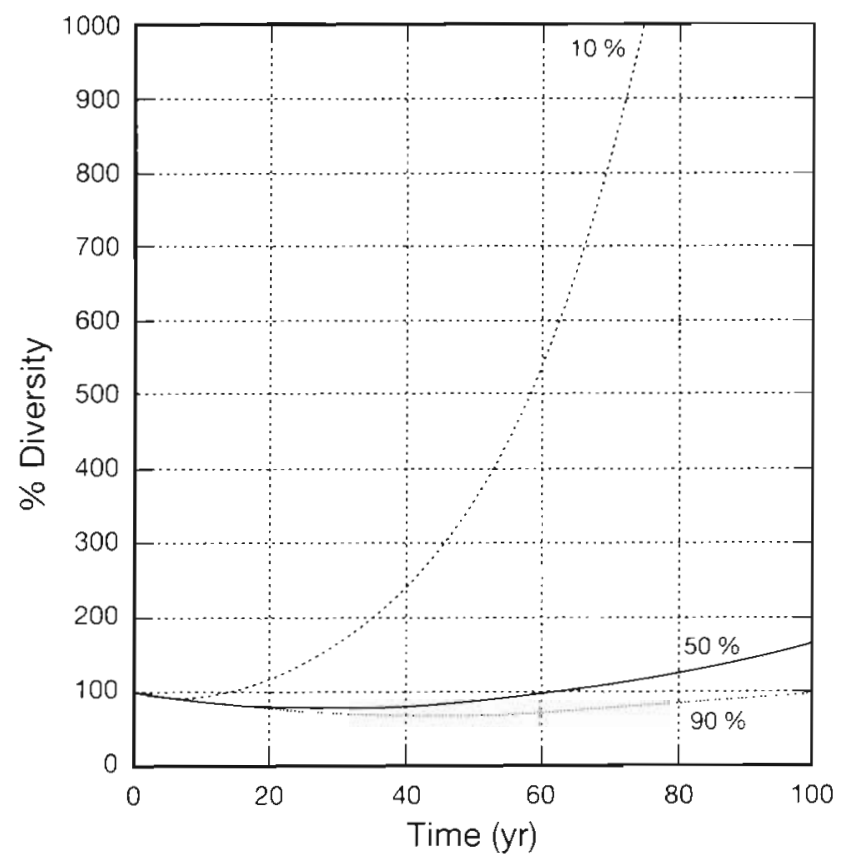

Fig. 2. Time graphs of changes in diversity as a function of the initially destroyed area. Inputs are similar to Fig. 1 except that $\mathrm{d} C / \mathrm{d} t=0.44$ and regrowth is $0.1 \% \mathrm{yr}^{-1}$ for 3 values of $C$ $(10,50$, and $90 \%)$. This figure illustrates only the moderate case effects of blast fishing. Constant rate coefficients are assumed 


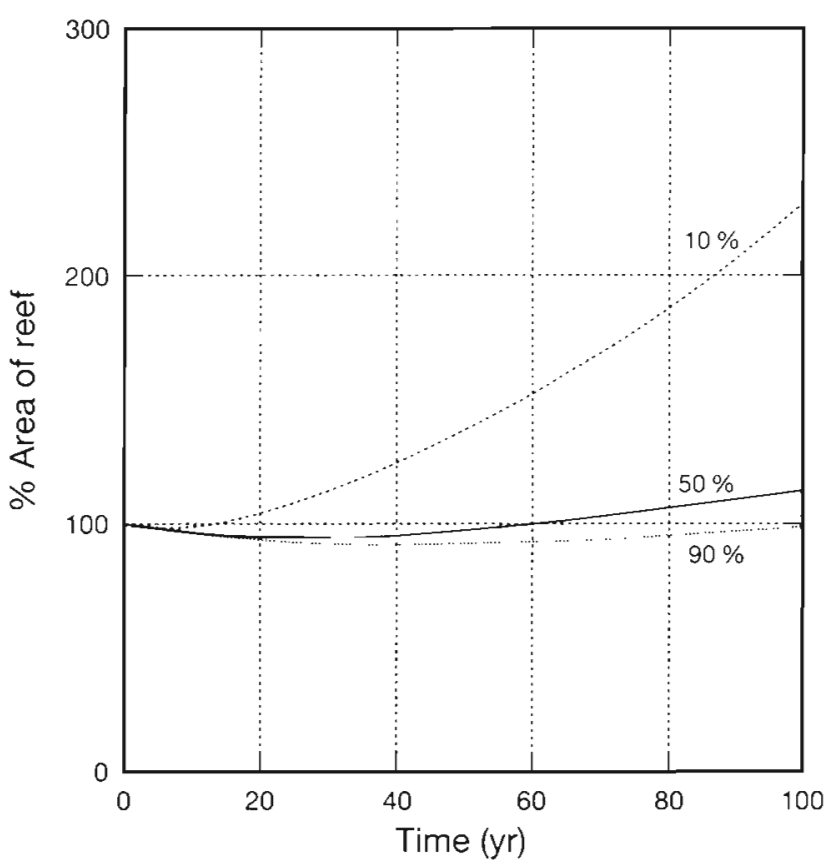

Fig. 3. Time graphs of changes in the area of the reef as a function of the initially destroyed area. All inputs and assumptions are similar to Fig. 2

The effects of an exponential model of increased reef destruction with parameters $b=2.5$ and $a=0.95$ and 0.80 respectively is illustrated (Fig. 5), using other inputs identical to Fig. 1. From this figure it is evident that the response in diversity is not especially sensitive to the exponential parameter a. Diversity is reduced in both cases for a period of about 40 yr to about $65 \%$ of the initial value. Recovery to approximately $100 \%$ of the initial value is indicated in $100 \mathrm{yr}$ for both values of the exponential model coefficient $a$. The exponential model offers considerable flexibility concerning the nature of increased/ decreased live coral destruction rates and is considered useful for further applications when more data are available.

The case is illustrated where blast fishing and anchor damage were assumed to occur but with no use of poisons (Fig. 6). The destructive fishing practices were assumed to follow a linear rate of increase model with a slope of $2.5 \%$. That is, $\mathrm{d} C / \mathrm{d} t=0.84 \%$ from blast fishing plus anchor damage; $C=50 \%$ and coral regrowth was assumed to be $1 \% \mathrm{yr}^{-1}$. This figure illustrates a slow but continuous increase in both diversity and area of live coral but with higher increases in diversity to about 1.40 times the initial value and area of coral cover to about 1.10 times the initial area in $100 \mathrm{yr}$. Note that this model time graph does not show any evidence of a decrease in diversity or live coral area during the entire simulation period.

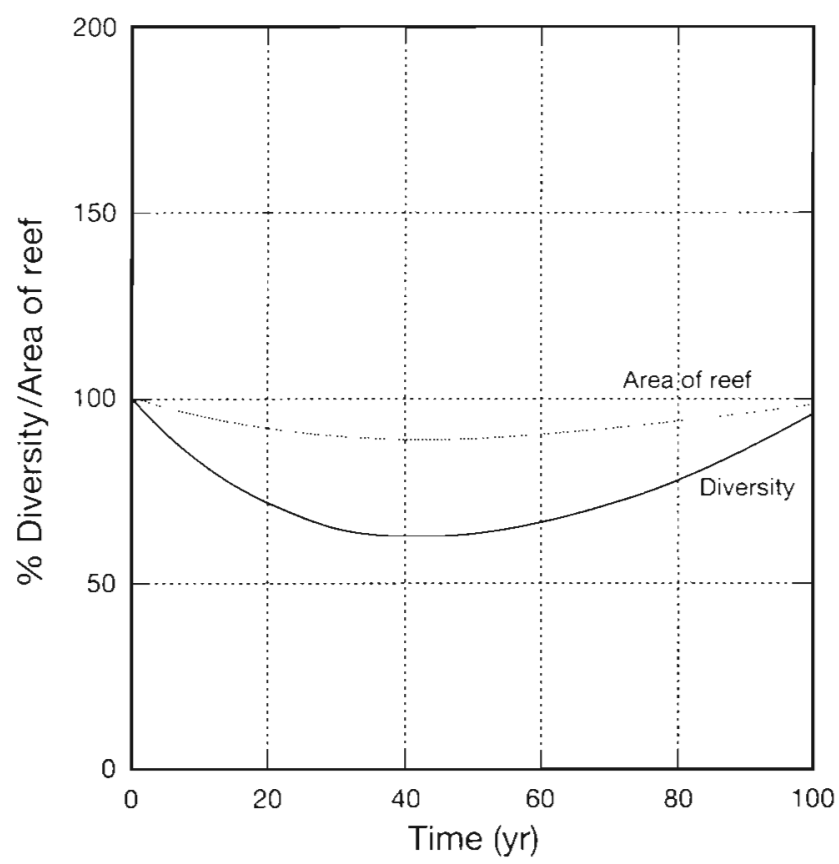

Fig. 4. Time graphs showing relationships between coral reef fish assemblage diversity and area of reef with coral cover over 100 yr. Alt inputs are similar to Fig. 1 except that a linear model of increasing coral reef destruction with $b$ (slope of regression line) $=2.5 \%$ is assumed

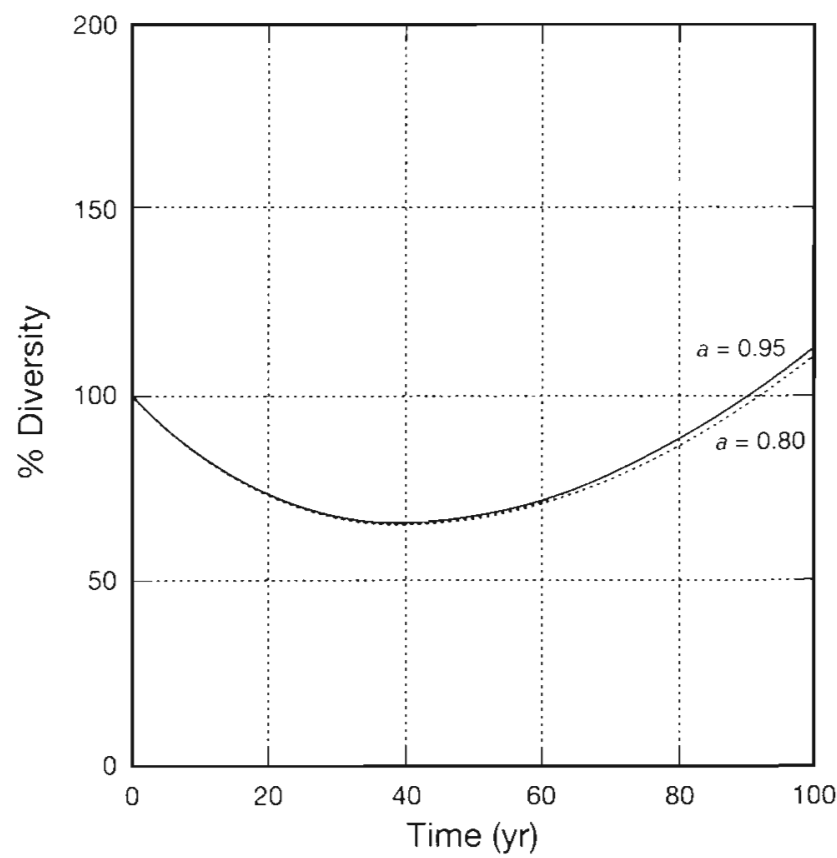

Fig. 5. Time graphs of changes in diversity using the same inputs as in Fig. 1 except that an exponential model of the rate of change of coral reef destruction is assumed with the exponential model coefficient $b=2.5$, and $a=0.95$ and $a=0.80$ 


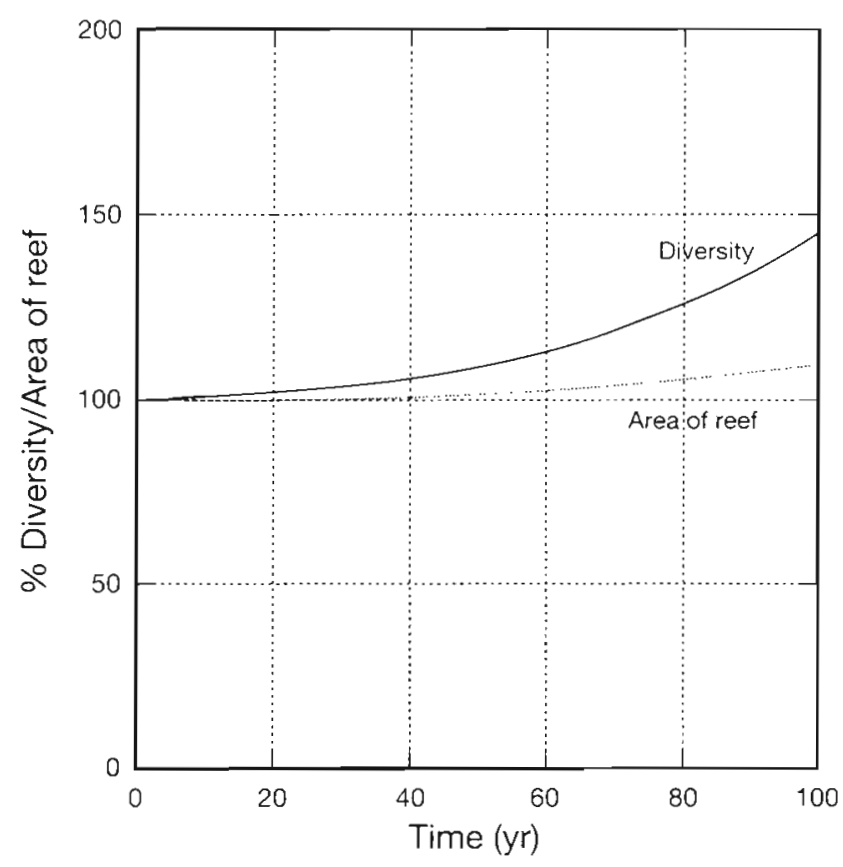

Fig. 6. Time graphs showing changes in diversity and area of live coral reef under simulated conditions of moderate levels of blast fishing and anchor damage but without use of poisons. The initial amount of destroyed area was $50 \%$. The slope of the linear model was $2.5 \%$, and the coral regrowth rate was assumed to be $1 \% \mathrm{yr}^{-1}$

\section{DISCUSSION}

Simulations using the model which has been described are believed to provide an overview of a complex system utilizing a minimum amount of detailed information. Although we have described predictions from the model under various scenarios, precise projections of responses from specific destructive fishing practices are not intended. However, we do believe the model is appropriate for examining the consequences of various assumptions and for examining some aspects of the behavior of this type of ecosystem. Following Kangas (1991) in expressing diversity and coral reef area as percentages permits our application of the model to a variety of situations.

Although it would have been desirable to include some formal measure of uncertainty in model outputs, this was not possible due to the paucity of data. However, we did perform a limited amount of sensitivity testing. For example, varying the exponent $Z$ in the interval $0.15 \leq Z \leq 0.35$ did not change diversity by more than about $2 \%$ above or below that observed with the standard value of 0.25 . We also exercised the model with the best and worst case scenarios taken from Table 1 as described in the results. We interpret the model output to be in relatively good agreement with some empirical data regarding relatively slow recovery in terms of coral regrowth and increases of diversity. These contrast with other reports (Brown et al. 1990) indicating rather rapid coral and diversity recovery (about $22 \mathrm{mo}$ ) from sedimentation. However, it must be recognized that this latter recovery occurred after cessation of the perturbation (dredging) whereas our model applies to continuing rates of reef destruction and regrowth of coral and changes in biodiversity.

The results from the first simulation study (Fig. 1) indicate that when using the moderate case estimates of the sum of the effects of blast fishing, anchor damage, and poisons to provide $\mathrm{d} C / \mathrm{d} t=2.84 \%$ in a constant rate model, with $C=50 \%$ and coral regrowth estimated at $1 \% \mathrm{yr}^{-1}$, both fish diversity and live coral reef cover are expected to decline for about $25 \mathrm{yr}$ before any recovery is expected. Recovery to initial conditions (i.e. those occurring at the start of the simulation when $50 \%$ of live coral was assumed to be destroyed) is expected to take about $60 \mathrm{yr}$. At the end of $100 \mathrm{yr}$ diversity is expected to have increased to 1.65 times the initial value and the area of coral regrowth to about 1.13 times its initial value. We interpret the time graph of Fig. 1 to provide information which is indicative of an unsatisfactory recovery schedule for both diversity and the regrowth of live coral area under current conditions. The fact that present conditions indicate a $50 \%$ loss of live cover suggests that the intensity of destructive fishing practices has been higher than is occurring at present. Some empirical evidence for this is presented in McManus et al. (1991). The projected slow recovery from coral regrowth is in keeping with results from studies of coral mining activities cited by Brown \& Dunne (1988) and by Allen (1992). Brown \& Dunne (1991) reported virtually no coral recovery in 16 yr after coral mining had ceased. Allen (1992) reports a wide range of coral recovery times extending from 5 to more than $30 \mathrm{yr}$. Our observations and model studies support conclusions concerning slow coral regrowth and recovery of biodiversity.

The results obtained in Figs. $2 \& 3$ are interpreted as indicating that the greater the extent of reef destruction assumed initially, the slower the period of recovery will be with respect to both diversity and living coral reef area. Slow regrowth of corals after destructive practices have ceased is evident from the literature, and these simulation models studies seem to reflect the observational data. Although the simulation results for the $10 \%$ initially destroyed area were included for nearly $80 \mathrm{yr}$ in Fig. 2 for diversity changes, we anticipate that diversity will have achieved an asymptotic level of the pristine state in something less than $40 \mathrm{yr}$ when the initial value of $50 \%$ of the remaining coral had doubled in magnitude from its starting value of 100 . Fig. 3 illustrates nearly the same results for the area of recovered coral reef. Recovery 
from the smallest amount of destruction assumed occurs at a more rapid rate than when a larger fraction of the area has been initially destroyed. However, coral area regrowth is nearly linear with a small slope (rate coefficient).

A linear model of increasing coral reef destruction where $b$, the slope of the linear model, is $2.5 \%$, was applied to the conditions described in Fig. 1 and is illustrated in Fig. 4. We interpret the results to demonstrate that any incremental increase in the rate of coral reef destruction from any cause(s) will significantly delay recovery and regrowth of corals or cause declines in coral cover and diversity even more than estimated from a constant-rate model. This figure illustrates that recovery to initial conditions has not occurred in the 100 yr simulation period.

Fig. 5 illustrates the application of an exponential model for reef destruction with parameter $b=2.5$ and the parameter $a$ varied between $a=0.95$ and $a=0.80$. Further decreases in diversity are illustrated, but later recovery seems a little better than in the linear model. Nevertheless, the model does not indicate satisfactory recovery time histories under the conditions tested. The flexibility of this model is considered to be high and useful for further application when more data are available.

The situation is illustrated where it is assumed that the total rate of reef destruction $\mathrm{d} C / \mathrm{d} t$ is reduced from 2.84 to 0.84 by elimination of the effects of the use of poisons in a constant rate model (Fig. 6). The results indicate that with the moderate rate of blast fishing plus the moderate rate of anchor damage, the recovery of both the diversity and the live coral reef area is modest but continually increasing. We interpret these results to mean that reduction of destructive fishing practices to the level of about $30 \%$ of the estimated total may be adequate to maintain present levels of coral reef area and diversity and may even permit a slow increase.

We conclude that the currently estimated destructive effects of blast fishing alone or blast fishing and anchor damage in coral reef areas for the moderate level case may be small enough to permit slow reef recovery and recovery of coral fish assemblage diversity.

We also conclude that the greater the initial damage to the coral reef habitat, the more difficult and timeconsuming will be the recovery process with respect to both coral cover and fish biodiversity.

We believe that combined efforts to reduce blast fishing activity, anchor damage, and the use of poisons may be most practical. If the current estimates of damage from the use of poisons are valid (Table 1), then it seems important to concentrate on reducing this effect. It seems possible that the destructive effects of blast fishing activities alone on coral reef regrowth and on fish diversity reduction may have been somewhat overemphasized in the past. Our observations on the major fish groups sought by blastfishers and the nature of fish kills from explosions support this statement. We also conclude that more precise estimates of current damage by use of poisons are highly desirable. If the data presented for the moderate case for use of poisons and anchor damage are valid, then reduction or elimination of these causes of live coral destruction may be more important than concentrating efforts on eliminating blast fishing.

Acknowledgements. This study was supported in part by USAID Grant No. DAN-4146-6-SS-507-00, which is intended to support collaborative work between the US and universities in developing countries.

\section{LITERATURE CITED}

Alcala, A. C., Gomez, E. D. (1987). Dynamiting coral reefs for fish: a resource destructive method. In: Salvat, B. (ed.) Human impacts on coral reefs: facts and recommendations. Antenne Museum EDHE, Moorea, p. 51-60

A.llen, W. H. (1992). Increased dangers to Caribbean marine ecosystems. Bioscience 42: 330-335

Arons, A. B. (1954). Underwater explosion shock wave parameters at large distances from the charge. J. Acoust. Soc. Am. 26: 343-346

Brown, B. E., Dunne, R. P. (1988). The impact of coral mining on coral reefs in the Maldives. Environ. Conserv. 15: $159-165$

Brown, B. E., LeTessier, M. D. A., Scoffin, T. P., Tudhope, A. W. (1990). Evaluation of the environmental impact of dredging on intertidal coral reefs at Ko Phuket, Thailand using ecological and physiological parameters. Mar. Ecol. Prog. Ser. 65(3): 273-281

Christian, E. A. (1973). The effects of underwater explosions on swimbladder fish. NOLTR 73-103, Naval Ordnance Laboratory, White Oak, Silver Spring, Maryland 20910

Galvez, R., Hingco, T. G., Bautista, C., Tungpalar, M. T. (1989). Socio-cultural dynamics of blast fishing and sodium cyanide fishing in the fishing villages in the Lingayen Gulf area. In: Silvestre, G., Miclat, E., Chua, T.-E. (eds.) Towards sustainable development of the coastal resources of the Lingayen Gulf, Philippines. ICLARM Conf. Proc. 17. Philippine Council for Aquatic and Marine Research and Development, Los Baños, Laguna, and International Center for Living Aquatic Resources Management. Makati, Metro Manila, Philippines, p. 43-62

Galvez, R., Sadorra, M. S. M. (1988). Blast fishing: a Philippine case study. Tropical Coastal Area Management 3(1): $9-10$

Gordon, M. S. (1970). Hydrostatic pressure. In: Hoar, W. S. Randall, D. J (eds.) Fish physiology, Vol. IV. The nervous system, circulation and respiration. Academic Press, New York, p. 445-461

Gould, S. J. (1979). An allometric interpretation of speciesarea curves: the meaning of the coefficient. Am. Nat. 114 $335-343$

Hogan, J (1941). The effects of high vacuum on fish. Trans. Am. Fish. Sci. 70: 469-474

Hubbs, C. L., Rechnitzer, A. B. (1952). Report on experiments 
designed to determine effects of underwater explosions on fish life. Calif. Fish Game 38(2): 333-366

Kangas, P. (1991). Macroscopic minimodels of deforestation and diversity. Ecol. Model. 57: 277-284

Ketchum, B. H. (ed.) (1972). The water's edge. Critical problems of the coastal zone. Coastal Zone Workshop. MIT Press, Cambridge, MA

Loehle, C. (1990). Proper statistical treatment of species-area data. Oihas 57: 143-146

Longhurst, A. R., Pauly, D. (1987). Ecology of tropical oceans. Academic Press, San Diego

Lovejoy, T. E. (1980). A projection of species extinctions. In: Barney, G. O. (Study Director). The Global 2000 Report of the President, 2. Council on Environmental Quality, U.S. Government Printing Office, Washington, DC, p. 329-331

McClanahan, T. (1992). Coral concerns. Bioscience 42: 741-742

McManus, J. W., Nanola, C. L., Reyes, R. P. Jr (1991). Destructive coral reef fishing: seeking perspectives. Working Paper No. 79. Fisheries Stock Assessment Title XII Collaborative Research Support Program. University of Rhode Island

NOL (Naval Ordnance Laboratory) (1947). Report of Conference on the Effect of Explosions on Marine Life. Naval Ordnance Laboratory Memorandum 9424. Cited in NOLTR 73-103

Pauly, D., Silvestre, G., Smith, I. R. (1989). On development, fisheries, and dynamite: a brief review of tropical fisheries management. Nat. Res. Modelling 3(3): 307-329

This article was presented by K. Sherman, Narragansett, Rhode Island, USA
Rubec, P. J. (1988). Cyanide fishing and the international marine life alliance net-training program. Tropical Coastal Area Management 3(1): 11-13

Russ, G. R. (1991). Coral reef fisheries: efforts and yields In: Sale, P. F. (ed.) The ecology of fishes on coral reefs. Academic Press, New York, p. 601-635

Schweitzer, J. (1992). Conserving biodiversity in developing countries. Fisheries 17(3): 31-34

Shephard, A. R. D., Warwick, R. M., Clarke, R. R., Brown, B. E. (1992). An analysis of fish community responses to coral mining in the Maldives. Environ. Biol. Fish 33: 367-380

Simberloff, D. (1986). Are we on the verge of mass extinctions in tropical rain forests? In: Elliott, D. K. (ed.) Dynamics of extinction. J. Wiley and Sons, New York, p. 165-180

Smith, S. V (1978). Coral reef area and the contributions of reefs to processes and resources of the world's oceans. Nature 273: 225-226

Soulé, M. E., Wilcox, B. A., Holtby, C. (1979). Benign neglect: a model of faunal collapse in game reserves of East Africa. Biol. Conserv. 15: 259-272

Sugihara, G. (1981). S = CA+, z 1/4: a reply to Connor and McCoy. Am. Nat. 117: 790-793

Wissel, C. (1992). Aims and limits of ecological modelling exemplified by island theory. Ecol. Model. 63: 1-12

Young, G. A. (1991). Concise methods for predicting the effects of underwater explosions on marine life. Naval Surface Warfare Center, Dahlgren, Virginia 22448. NAVSWC MP $91-220$

Manuscript first received: August 15, 1992

Revised version accepted: January 8, 1993 